\title{
Publisher's Note: Transverse mode coupling instability of colliding beams [Phys. Rev. ST Accel. Beams 17, 041002 (2014)]
}

S. White, X. Buffat, N. Mounet, and T. Pieloni (Received 15 April 2014; published 21 April 2014)

DOI: 10.1103/PhysRevSTAB.17.049902

PACS numbers: 29.20.-c, 29.27.-a, 07.05.Tp, 99.10.Fg

This paper was published online on 9 April 2014 with an omission in the Acknowledgments. The additional sentence should read as "This research has used resources of the High Performance Computing center of the Ecole Polytechnique Federale de Lausanne, which was supported by the Laboratory of Particle Accelerators Physics." The Acknowledgments have been corrected online as of 11 April 2014.

Published by the American Physical Society under the terms of the Creative Commons Attribution 3.0 License. Further distribution of this work must maintain attribution to the author(s) and the published article's title, journal citation, and DOI. 